\title{
A Switched Reluctance Generator Behavior under Variable Speed and Variable Excitation
}

\author{
Ribeiro, F. S. L., Cabral L. G., Fleury, A. \\ Laboratório de Máquinas Elétricas da Universidade Católica de Goiás \\ Praça Universitária, 1440, Goiânia - Go \\ filipe_ee@yahoo.com.br; ludmyllacabral@ hotmail.com; afleury@terra.com.br
}

\begin{abstract}
The subject of this paper is the wind powered Switched Reluctance Generator - SRG and its behavior. Simulations and experimental results are presented. It was analyzed the efficiency of SRG under different conditions. Many operational test were conduced to state clearly the behavior of a prototype drove by a half-bridge (HB) converter. Variable excitation voltage and angular speed relationship is clearly established. It shows that the suitable excitation control for a wind powered SRG must adjust the operation parameters to match the desired point on certain surfaces.
\end{abstract}

\section{Key words}

Switched Reluctance Generator, wind power, variable speed.

\section{Introduction}

Currently, due the large global consumption of power, researches on renewable energy sources, like photovoltaic, wind power, biomass and others are being conducted. Although the uncertainties in the availability of the renewable energy sources are a fact. And so it is difficult to operate a power system based only on renewable sources [1].

Among all the renewable energy sources wind power presents the higher global growth in the last years. By having large geographic opening it can generate electrical energy close to the load centers avoiding the construction of large transmission lines. Wind power does not damages the environment. The verticality of the towers allows the use of the ground below the wind turbines for agriculture.

This paper proposes the Switched Reluctance Generator - SRG as an special electrical generator for wind power. A PWM inverter can be used to adjust the output as required.

A prototype was built and tested to know the operational behavior of this kind of machine under variable excitation and variable speed. The results are presented here. Through these tests the need of a specific control of the excitation voltage is proved for the wind powered SRG systems.

\section{Energy Conversion}

In a SRG mechanical power achieved from a prime mover through a shaft is converted into electrical power. When a pole of the rotor is aligned with the excited pole of the stator, there is a state of stable equilibrium. Thus, in the SRG there is a natural tendency to align the rotor and the stator active poles in order to maximize de inductance of that phase. When an external mechanical agent forces the rotor to leave the stable equilibrium position, the electromagnetic torque produced results in a back electromotive force that increases the applied voltage. In this way the machine generates electrical power.

The electrical equation for a phase of the $S R G$ is:

$$
v=R i+L \frac{d i}{d t}+e
$$

The back electromotive force is given by:

$$
e=i \cdot \omega \cdot \frac{\partial L}{\partial \theta}
$$

where:

$$
\omega=\frac{d \theta}{d t}
$$

The stator winding is fed in DC. As $\omega$ and $i$ are both positive, the sign of $e$ is the same as that of $\frac{\partial L}{\partial \theta}$. From (2) it can be seen that when $\frac{\partial L}{\partial \theta}>0$ the back electromotive force is positive. In this case, electric power is converted to mechanical power and the machine works as a motor. But when $\frac{\partial L}{\partial \theta}<0$ the back electromotive force is negative and it increases the current converting mechanical power into electrical power [2].

The dynamic mechanical equation for the SRG is given by (3). It is to be noted that the electromagnetic torque $C_{\text {emag }}$ comes as a negative quantity, i. e., acting against the rotor mechanical speed.

$$
C_{m}+C_{\text {emag }}-J \frac{d \omega}{d t}-D . \omega=0
$$

The co-energy of a phase of this machine is given by:

$$
W^{c o}=\int_{0}^{i} \lambda d i
$$


And the corresponding electromagnetic torque for an $n$ phase SRG is given by:

$$
C_{\text {emag }}=\frac{\partial W_{a}^{c o}}{\partial \theta}+\frac{\partial W_{b}^{c o}}{\partial \theta}+\frac{\partial W_{c}^{c o}}{\partial \theta}
$$

The mathematical model of a $6 \times 4 \mathrm{SRG}$ is shown below:

$$
\begin{aligned}
{\left[\begin{array}{c}
v_{a} \\
v_{b} \\
v_{c} \\
C_{m} \\
0
\end{array}\right] } & {\left[\begin{array}{ccccc}
R_{a} & 0 & 0 & 0 & 0 \\
0 & R_{b} & 0 & 0 & 0 \\
0 & 0 & R_{c} & 0 & 0 \\
-r_{a} / i_{a} & -r_{b} / i_{b} & -r_{c} / i_{c} & D & 0 \\
0 & 0 & 0 & -1 & 0
\end{array}\right] \cdot\left[\begin{array}{c}
i_{a} \\
i_{b} \\
i_{c} \\
\omega \\
\theta
\end{array}\right]+} \\
+ & {\left[\begin{array}{ccccc}
L_{a} & 0 & 0 & 0 & i_{a} \frac{\partial L_{a}}{\partial \theta} \\
0 & L_{b} & 0 & 0 & i_{b} \frac{\partial L_{b}}{\partial \theta} \\
0 & 0 & L_{c} & 0 & i_{a} \frac{\partial L_{c}}{\partial \theta} \\
0 & 0 & 0 & J & 0 \\
0 & 0 & 0 & 0 & 1
\end{array}\right] \cdot\left[\begin{array}{c}
\dot{i}_{a} \\
\dot{i}_{b} \\
\dot{i_{c}} \\
\dot{\omega} \\
\dot{\theta}
\end{array}\right] }
\end{aligned}
$$

where:

$$
r_{a}=\frac{\partial W_{a}^{c o}}{\partial \theta} ; r_{b}=\frac{\partial W_{b}^{c o}}{\partial \theta} \text { And } r_{c}=\frac{\partial W_{c}^{c o}}{\partial \theta}
$$

\section{Wind behavior}

The wind is an intermittent and variable energy source both in magnitude and in direction. There are several components in the wind speed [3], for example:

$$
V_{\text {wind }}=V_{\text {base }}+V_{\text {ramp }}+V_{\text {gust }}+V_{\text {noise }}
$$

The wind turbines has its power as a function of the wind speed cube as showed below.

$$
P_{\text {turbine }}=\frac{1}{2} C_{p} \cdot \rho \cdot A \cdot V_{\text {wind }}^{3}
$$

$\rho=$ air specific weight

$\mathrm{A}=$ swept area of the blades

$C_{p}=$ Power Coefficient

The power coefficient $C_{p}$ is the fraction of the wind kinetic power that is captured by the wind turbine blades [4]. It is the efficiency of the rotor. This coefficient changes from turbine to turbine and its value is given by:

$$
C_{p}=\frac{\left(1+\frac{V_{0}}{V}\right)\left[1-\left(\frac{V_{0}}{V}\right)^{2}\right]}{2}
$$

where $v_{0}$ is the wind speed after turbine and. This function is described in Fig. 1.

It can be seem that this coefficient is maximum at around 0.59 , then the maximum transfer of energy takes place with almost $60 \%$ of the initial value. For turbines of three blades and low speed - the most used -, the efficiency of the rotor is between 0.2 and 0.4 .

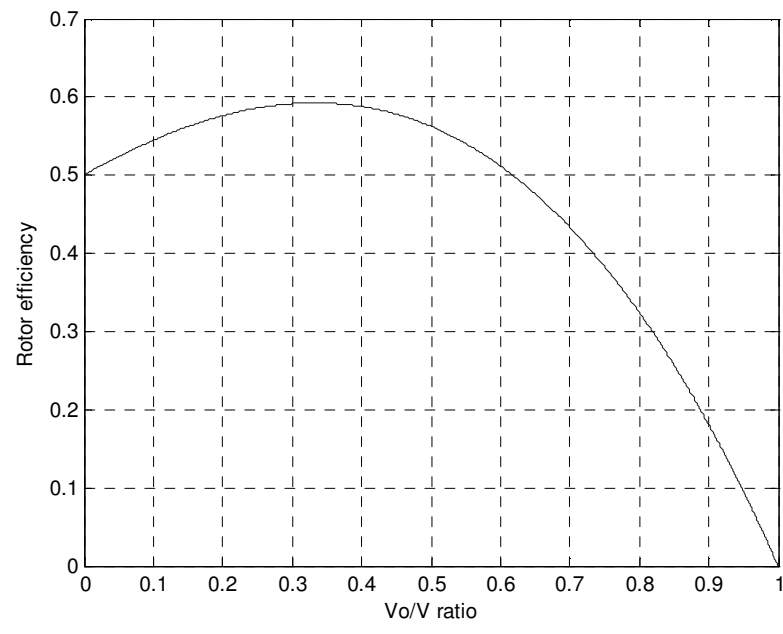

Fig. 1 Power coefficient versus speed ratio for a generic wind turbine.

It is a consensual appreciation that the wind speed in a certain site follows the Weibull probability distribution function like this:

$$
p\left(v_{i}\right)=\left(\frac{k}{c}\right)\left(\frac{v_{i}}{c}\right)^{k-1} e^{-\left(\frac{v_{i}}{c}\right)^{k}}
$$

Where $p\left(v_{i}\right)$ is the fraction of time where wind speed is between $v_{i}$ and $v_{i}+\Delta v_{i}$, divided by $\Delta v_{i}, c$ is a scale parameter and $k$ is a shape parameter. Generally $p\left(v_{i}\right)$ is expressed in hours per year per $m / s$. On most places c varies from 5 to $10 \mathrm{~m} / \mathrm{s}$ and $\mathrm{k}$ varies between 1.5 and 2.5. Fig. 1 shows the curves of Weibull probability distribution for the shape factor $\mathrm{k}=2$ where the scale parameter varies between $5 \mathrm{~m} / \mathrm{s}$ and $13 \mathrm{~m} / \mathrm{s}$.

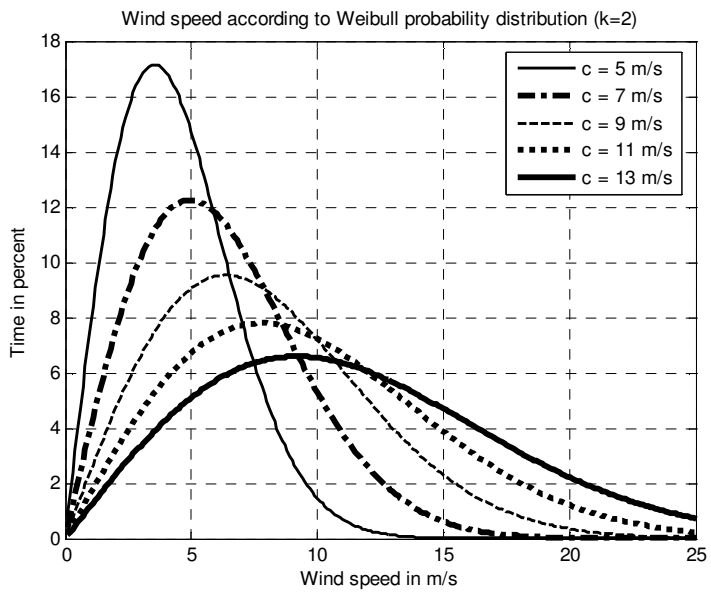

Fig. 2. Wind speed permanency curves.

Fig. 2 shows that the wind speed is low most of the time. The rotor speed has the same behavior of the wind speed. A generation has to follow this profile should start with low wind speeds and increase the generation with the increase of wind speed.

In the experimental results is shown that the behavior of the SRG fits the profiles of wind of the curves of Weibull. 


\section{Simulations}

The simulations were done using data from a small prototype of SRG. Its parameters and dimensions are given in Table I.

TABLE I. - Characteristics of SRG used

\begin{tabular}{|l|c|c|}
\hline \multicolumn{1}{|c|}{ Parameter } & Value & Units \\
\hline Stator Diameter & 140 & $\mathrm{~mm}$ \\
\hline Rotor Diameter & 70 & $\mathrm{~mm}$ \\
\hline Stack Length & 107 & $\mathrm{~mm}$ \\
\hline Air Gap Length & 0.4 & $\mathrm{~mm}$ \\
\hline Stator Teeth Width & 19 & $\mathrm{~mm}$ \\
\hline Rotor Teeth Width & 20 & $\mathrm{~mm}$ \\
\hline Stator Slot & 22.5 & $\mathrm{~mm}$ \\
\hline Rotor Slot & 11.7 & $\mathrm{~mm}$ \\
\hline Stator Yoke & 12 & $\mathrm{~mm}$ \\
\hline Rotor Yoke & 12.4 & $\mathrm{~mm}$ \\
\hline Shaft Diameter & 22 & $\mathrm{~mm}$ \\
\hline $\begin{array}{l}\text { Number of turns per } \\
\text { phase }\end{array}$ & 50 & turns/phase \\
\hline Inertia & 0.0028 & $\mathrm{~kg} . \mathrm{m}^{2}$ \\
\hline Coefficient of Friction & 0.026 & $\mathrm{~N} . \mathrm{m} . \mathrm{s}$ \\
\hline $\begin{array}{l}\text { Inductance (Aligned } \\
\text { Position) }\end{array}$ & 36 & $\mathrm{mH}$ \\
\hline $\begin{array}{l}\text { Inductance (Unaligned } \\
\text { Position) }\end{array}$ & 3 & $\mathrm{mH}$ \\
\hline
\end{tabular}

Each phase winding has 50 turns of copper wire AWG 15. The driving strategy states that each phase is fired during 30 degrees and just one phase is fired at time.

The SRG was simulated under different conditions. Simulation results at a typical speed of $900 \mathrm{rpm}$ are presented. Figure 2 shows the DC voltages and currents at the input (VE, IE) and at the output (VS, IS) of the converter.

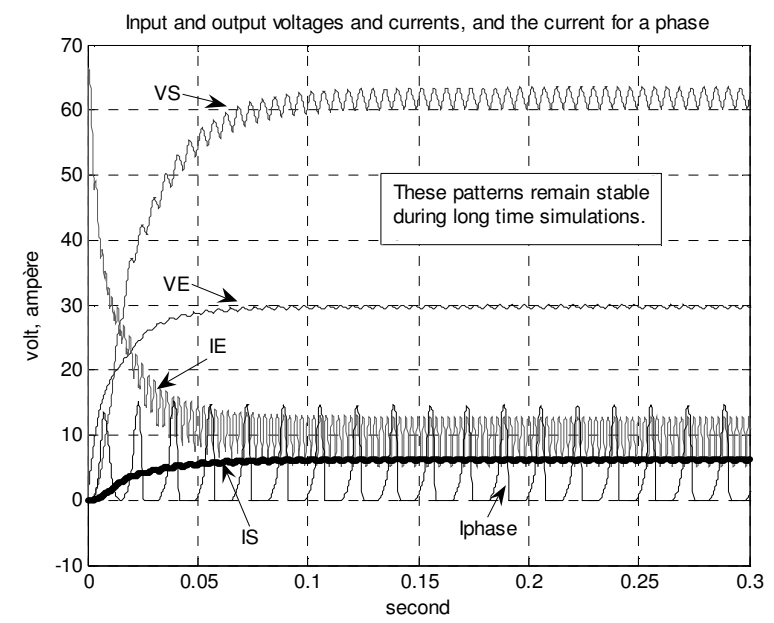

Fig. 3 Input and Output voltages and currents and a phase current

Fig. 3 also shows the phase current. Fig. 4 shows the simulation results for the winding voltage, the excitation current, and the current of power transfer to the load are. These are the voltage and the current for a single winding during the excitation and the generation periods. It could be seen there that when the excitation ended, the back EMF became negative, supplying additional power to the load.

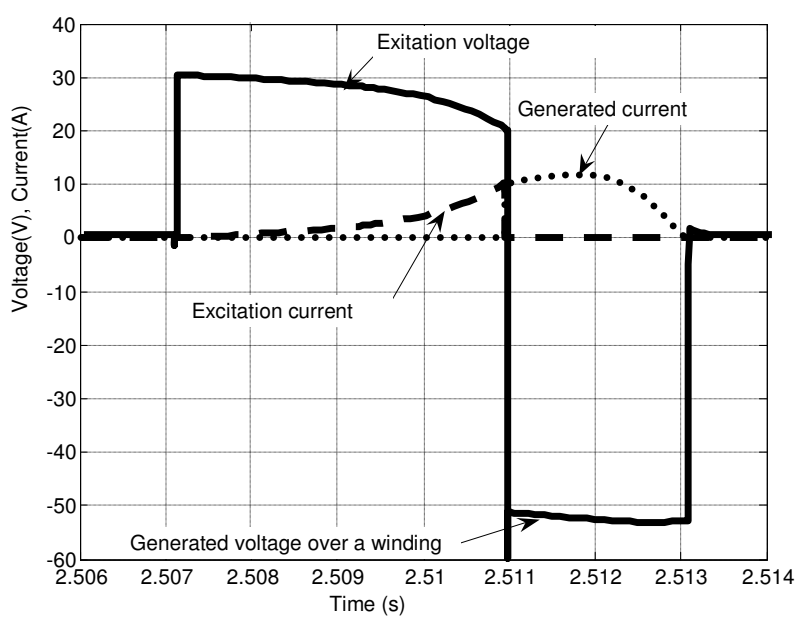

Fig. 4. Dynamics of power generation at a phase.

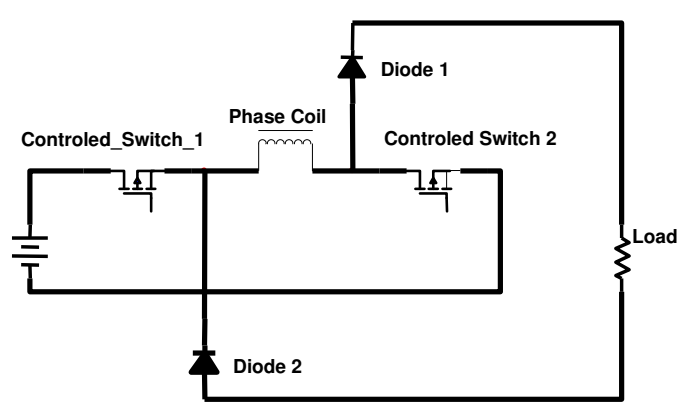

Fig. 5 - Electrical scheme of the half-bridge converter.

Fig. 5 shows the electrical scheme of the one phase. The excitation period begins when the controlled switches is turned on, the inductance is still increasing, the diodes are off and the phase winding generates a positive back EMF. The generating period begins when the controlled switches is turned off, the inductance is now decreasing, the diodes are on and the phase winding under a negative back EMF.

\section{Experimental Results}

The control of the power delivered to the load is a constant challenge. Since wind speed is variable the excitation voltage must be controlled to make the generated power as constant as possible. For the prototype built the greatest power generation occurs at around $1300 \mathrm{rpm}$ as it can be seen in Fig.6. This Fig. 6 also shows the power generated by the prototype of the SRG with 6 poles in the stator and 4 poles in the rotor, excited by $29 \mathrm{~V}$, from $500 \mathrm{rpm}$ up to $5000 \mathrm{rpm}$. This result 
shows that the SRG fits into the characteristic of angular speeds expected from the wind turbines which work in places of lower average speed of wind.

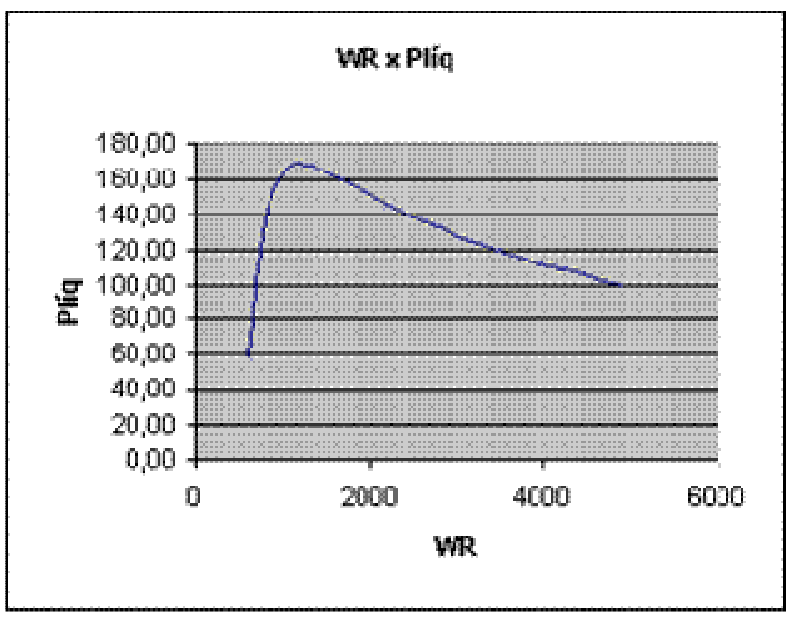

Fig. 6 Generated power in function of angular speed (rpm) for SRG .

Observing Fig. 6 one can note that the changes of speed cause an inconstancy in the power generated. In order to keep this output variable constant the excitation voltage must be controlled.

For the prototype built it was kept a collection of data for variable angular speed and excitation. Through these measures generated a function of the type:

$$
P_{g}=P_{g}(\omega, V)
$$

Where $\mathrm{Pg}$ is the generated power. This graphic is shown in Fig. 7. The excitation voltage was also changed from $5 \mathrm{~V}$ to $39 \mathrm{~V}$ and for each excitation voltage the speed of machine was changed from 450 to $4800 \mathrm{rpm}$.

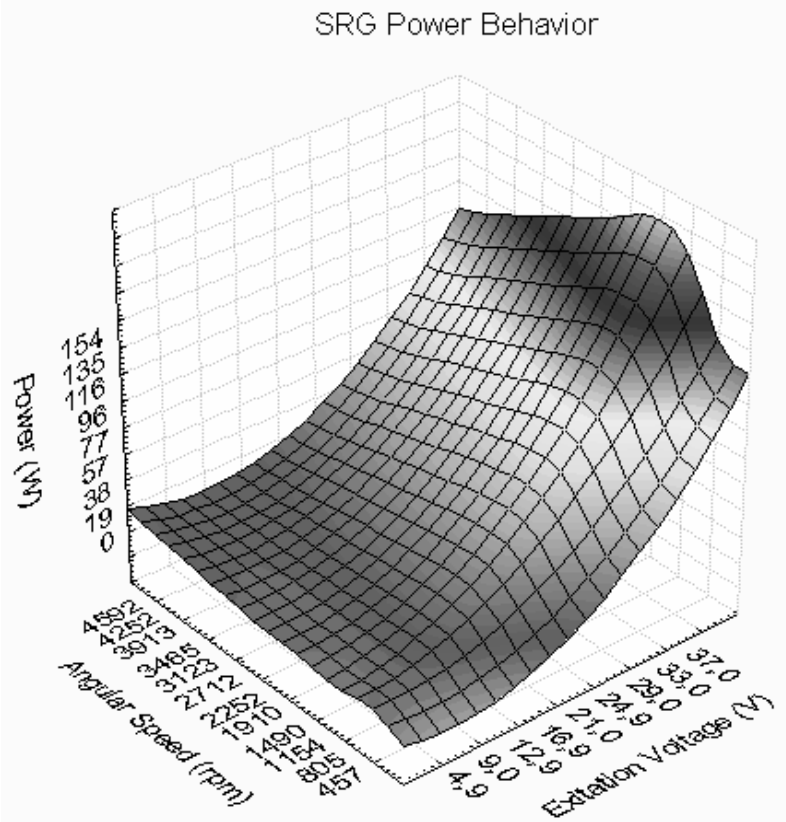

Fig. 7 Power generated, excitation voltage and angular speed.

Through it is clear that the better angular speeds for this prototype are between 1100 and $1300 \mathrm{rpm}$ depending on the excitation voltage. As earlier said the wind speed is not constant and it cannot be controlled. So excitation voltage should be controlled in order to obtain the best performance of the SRG. It is quite apparent that for each angular speed one can control the power generated through the excitation voltage.

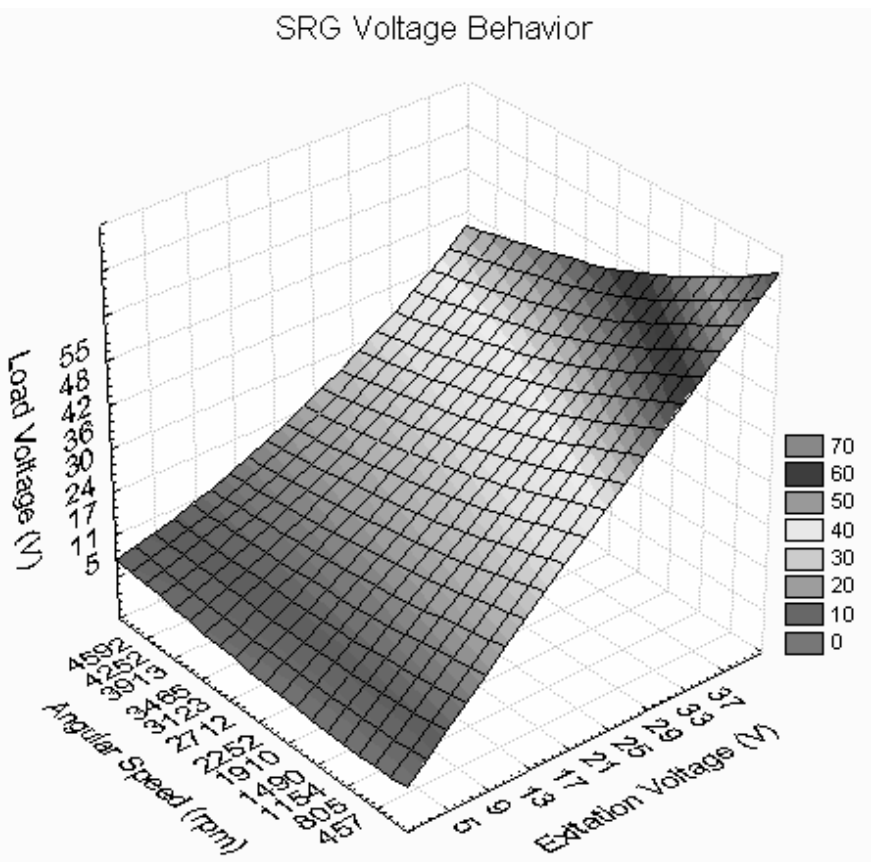

Fig. 8 Tensão na carga, tensão de excitação e velocidade angular.

Fig 8 shows that load voltage obviously also can be stabilized adjusting the excitation. This experimental results confirm that the control of the rectifier output to the converter can be used stabilize the output voltage to the load, improving the global performance.

The two curves (7) e (8) make evident that the behavior of the prototype in a large scale variation of the parameters angular speed and excitation voltage. With these parameters detected and controlled one can predict the behavior of the prototype in many situations. And yet show what are the best parameters to get more efficiency.

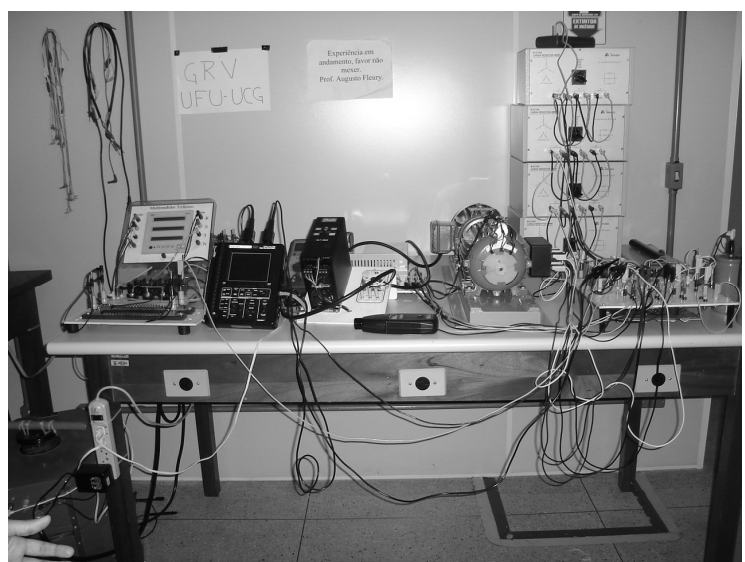

Fig. 8 Prototype of the SRG 


\section{Conclusion}

The prototype built and the results obtained confirm that the application of the Switched Reluctance Generator for wind power plants is suitable. As the wind is not constant it is indispensable an adjustment in the excitation voltage to control the output power or voltage.

The operational behavior obtained with angular speed, excitation voltage and output power, showed that the control of the excitation voltage is an effective way to control the SRG performance.

Is was also noticed that high speeds of wind do not improve the output power, as the best greatest power was generated at around the angular speed of 1300rpm .

Analyzing the load voltage it can be noticed that it also can be stabilized when the excitation voltage is under control.

Using the converter showed in Fig. 5 it is possible to control the load voltage.

\section{Acknowledgement}

The authors thanks Universidade Estadual de Goiás and Universidade Católica de Goiás for all supports provided .

\section{References}

[1] F. Blaabjerj, F.Iov, "Wind power - A power source now enabled by power electronics," in $9^{\text {th }}$ Brazilian Power Electronics Conference, september, 30 to October,3,2007, Blumenau, Brasil.

[2] Sawata, Tadashi (2001). The switched reluctance generator, Electronic Control of Switched Reluctance Machines, Newness Power Engineering Series, Ed. T. J. E. Miller, Oxford, pp. 227-251.

[3] Z. Chen and E. Spooner, "Grid Power Quality with Variable Speed Wind Turbines" in IEE Transactions on Energy Conversion, vol. 16, No. 2, June 2001

[4] M. R. Patel, "Wind and solar power systems". CRC Press, New York, 1999. 